УДК 547.972

\title{
ФЕНОЛЬНЫЕ СОЕДИНЕНИЯ НАДЗЕМНОЙ ЧАСТИ GERANIUM CHARLESII (AITCH. \& HEMSL.) VVED.
}

\author{
(ㄱ Д.Р. Сиддиков", Х.М. Бобакулов, С.3. Нишанбаев, Н.Д. Абдуллаев \\ Институт химии растительных веществ им. акад. С.Ю. Юнусова АН РУз, \\ ул. М. Улугбека, 77, Ташкент, 100170 (Узбекистан), e-mail: drsiddiqov@mail.ru
}

Исследованы фенольные соединения надземной части (стебли, листья и цветки) Geranium charlesii (Aitch. \& Hemsl.) Vved. (Герань Чарльза семейство Geraniaceae), произрастающего в Узбекистане. Впервые из данного вида герани методом колоночной хроматографии из этилацетатной и $\boldsymbol{t}$-бутанольной фракции $70 \%$ этанольного экстракта последовательно выделены фенольные соединения. При разделении этилацетатной фракции на хроматографической колонке выделены пять индивидуальных веществ, в том числе галловая кислота (1), метилгаллат (2), кемпферол (3), кверцетин (4), изорамнетин (5), а из $\mu$-бутанольной фракции - изорамнетин 3-O- $\beta$-D-глюкопиранозида (6), изокверцитрина (7), изорамнетин 3-O-вицианозида (8).

Согласно проведенным фитохимическим исследованиям, впервые показано, что надземная часть растения G. charlesii является источником биологически активных фенольных соединений 1-8. Следует отметить, что соединения 1-4 и 7 ранее были выделены из Geranium saxatile и Geranium tuberosum L. subsp. tuberosum, a 5, 6, 8 впервые были выделены из Geranium charlesii и в целом из растения рода Geranium. Преобладающими по содержанию этого вида Geranium являются галловая кислота (1) и изорамнетин 3-О-вицианозид (8). Полученные соединения идентифицированы на основании результатов УФ-, ИК-, ЯМР-спектроскопии и масс-спектрометрии.

Ключевые слова: Geranium charlesii (Aitch. \& Hemsl.) Vved., Geraniaceae, фенолкарбоновая кислота, флавонолы и флавонолгликозиды.

Работа выполнена при финансовой поддержке программ фундаментальных научных исследований АН РУз (грант ФА-Ф7-Т 184; грант ФА-Ф7-Т 185).

\section{Введение}

Герань (Geranium L.) - род растений семейства Geraniaceae, включает в себя около 300 видов [1]. На территории стран СНГ произрастает около 55 видов [2], в Средней Азии - 21 вид [3]. На территории Узбекистана встречается 13 видов Geranium L. [4, 5], которые используются в народной медицине в качестве вяжущего, слабого дезинфицирующего, гемостатического и противовоспалительного средств, для лечения злокачественных опухолей, при диарее, дизентерии, коликах, бессоннице, эпилепсии, лихорадке, ревматизме и других заболеваниях [6].

Сиддиков Дониёр Рахимович - младший научный

сотрудник лаборатории химии кумаринов и терпеноидов, e-mail: drsiddiqov@mail.ru

Бобакулов Хайрулла Мамадиевич - кандидат химических наук, старший научный сотрудник лаборатории физических методов исследований, e-mail:khayrulla@rambler.ru

Нишанбаев Сабир Зарипбаевич - кандидат химических наук, старший научный сотрудник лаборатории физических методов исследований, e-mail: sabir78@rambler.ru

Абдуллаев Насрулла Джалилович - кандидат химических наук, ведущий научный сотрудник лаборатории физических методов исследований, e-mail: n_abdullaev@rambler.ru

\section{Проведенные} фармакологические биологические исследования фенольных соединений, выделенных из растений рода Geranium L. (флавоноиды, в том числе проантоцианидины и другие), показали, что они обладают широким спектром биологической активности, а именно: противовирусным, противомикробным, гипогликемическим, антидиарейным, антиоксидантным, диуретическим, антипротозойным, противовоспалительным действием [7-14].

Представляет интерес надземная часть Geranium charlesii (Aitch.\& Hemsl.) Vved. (герань

\footnotetext{
* Автор, с которым следует вести переписку.
} 
Чарльза) - многолетнее травянистое растение, распространенное на территории Узбекистана, явившееся объектом нашего исследования.

Химический состав вида $G$. charlesii, произрастающего в Узбекистане, не исследован. Однако в литературе имеются данные об обнаружении дубильных веществ (6,38\%) в надземной части G. charlesii [15]. Поэтому мы сочли целесообразным провести глубокое химическое изучение фенольных соединений этого вида.

\section{Экспериментальная часть}

Обьект исследования. Надземная часть G. charlesii заготовлена в период цветения (апрель 2014 г.) в окрестностях села Омонхона Байсунского района Сурхандарьинской области. Видовую принадлежность определяли сопоставлением собранных гербарных образцов с гербарным материалом G. charlesii, хранящимся в Центральном гербарии Узбекистана (объединенные гербарии Ташкентского государственного университета и Института генофонда растительного и животного мира АН РУз).

Для изучения состава фенольных соединений из надземной части был получен экстракт на $70 \%$ этаноле и разделен на ряд фракций. Для этого высушенную и измельченную надземную часть $(2,9$ кг) пятикратно экстрагировали методом настаивания (соотношение сырья - растворителя $1: 6,24$ ч) при комнатной температуре последовательно экстракционным бензином, хлороформом (для отделения липидоподобных и других неполярных веществ), затем 70\% этанолом (для отделения фенольных соединений). Полученное этанольное извлечение отделяли от обработанного сырья процеживанием через фильтровальную бумагу, растворитель удаляли под вакуумом, остаток высушивали, выход экстрактивных веществ составил 861 г (29,7\% от воздушно-сухого сырья). Этанольный экстракт растворили в небольшом количестве $70 \%$ этанола и смешали с силикагелем КСК (100-200 меш) при соотношении 1 : 1. Высушенную массу поместили на делительную воронку и последовательно фракционировали хлороформом, этилацетатом, $\mu$-бутанолом, метанолом и дистиллированной водой.

Выделение индивидуальных соединений из этилацетатной фракции проводили методом адсорбционной колоночной хроматографии на силикагеле. Этилацетатную фракцию 35,0 г помещали на колонку с силикагелем КСК (100/200 мкм, КСК фирмы Tianjin Sinomed Pharmaceutical, Китай), соотношение сорбент - фракция 1 : 20, высота колонки - 165 см, диаметр - 4,5 см, высота слоя сорбента - 126 см, высота слоя сорбента с фракцией - 135 см. Элюирование проводили хлороформом, смесью хлороформ - метанол, постепенно повышая градиент последнего. Затем проводили рехроматографирование отдельных элюатов на сефадексе LH-20 (GE Healthcare Bio-Sciences AB, Швеция), элюируя смесью вода - метанол с нарастающим градиентом концентрации метанола. Аналогично проводили разделение $н$-бутанольной фракции в количестве 48 г, при этом соотношение сорбент - фракция $1: 20$, высота колонки - 190 см, диаметр 4,5 см, высота слоя сорбента - 170 см, высота слоя сорбента с фракцией 182 см.

Тонкослойную хроматографию (ТCX) проводили на пластинках Silufol UV-254. Для ТСХ флавоноидов использовали системы растворителей: хлороформ - метанол - уксусная кислота - вода $(9: 3: 0,5: 0,5$; $7: 3: 0,5: 0,5)$. На хроматограммах фенольные соединения обнаруживали по характерному свечению в УФсвете при длине волны 254 нм или 365 нм, а также после обработки хроматограмм парами аммиака, 1\% спиртовым раствором алюминия хлорида и $1 \%$ раствором ванилина в $5 \%$ спиртовом растворе серной кислоты.

Моносахаридный состав изорамнетин 3-О-вицианозида определяли после полного кислотного гидролиза 2 н. $\mathrm{H}_{2} \mathrm{SO}_{4}$ в течение 8 ч при температуре $100^{\circ} \mathrm{C}$. Гидролизат нейтрализовали $\mathrm{BaCO}_{3}$, деионизировали катионитом КУ-2 $\left(\mathrm{H}^{+}\right)$и исследовали с помощью бумажной хроматографии (Filtrak № 12) в системе растворителей: $\mu$-бутанол - пиридин - вода $(6: 4: 3)$ с использованием известных свидетелей (D-галактоза, $D$-глюкоза, $L$-арабиноза, $D$-ксилоза и $L$-рамноза). Далее хроматограмму опрыскивали кислым анилинфталатом с последующим нагреванием в течение 3-5 мин при $90-100{ }^{\circ} \mathrm{C}$.

Инфракрасные спектры выделенных веществ снимали на приборе System 2000 FT IR (Perkin Elmer, США) в виде таблеток с KBr. УФ-спектры сняты в спиртовом растворе на приборе Lambda-16 (Perkin Elmer, США), масс-спектры - на приборе AxIon 2 TOF MS (Perkin Elmer, США). ${ }^{1} \mathrm{H},{ }^{13} \mathrm{C}$ ЯМР-спектры снимали на приборе Unity 400 plus (Varian, США, 400 МГц для ${ }^{1} \mathrm{H}$ и 100 МГц для ${ }^{13} \mathrm{C}$ ) в растворах Ру- $d_{5}$, ДМCO- $d_{6}$ и $\mathrm{CD}_{3} \mathrm{OD}$. В качестве внутреннего стандарта в спектрах ${ }^{1} \mathrm{H}$ ЯМР использовали ГМДС (0 м.д.).

\section{Обсуждение результатов}

В результате разделения этанольного экстракта получены 3,1 г хлороформной, 35 г этилацетатной, 118 г н-бутанольной, 450 г метанольной и 75,5 г водной фракции. 
При разделения этилацетатной фракции (35 г) на хроматографической колонке, элюируя системами хлороформ, хлороформ - метанол в различных соотношениях и дальнейшем рехроматографировании отдельных элюатов на сефадексе LH-20, элюируя смесью вода - метанол с нарастающим градиентом концентрации спирта, выделили пять индивидуальных веществ (1-5), а из н-бутанольной фракции (48 г) - три (6-8). На основании хроматографического изучения при сравнении их со стандартными образцами методом ТСХ соединения 1 и 2 отнесены к производным фенолкарбоновой кислоты, а соединения 3-8 - к производным флавонола.

Структуры всех выделенных соединений подтверждены физико-химическими методами (УФ-, ИК-, ${ }^{1} \mathrm{H}$ ЯМР- и ${ }^{13} \mathrm{C}$ ЯМР-спектров) при сопоставлении с литературными данными.

Галловая кислота (3,4,5-тригидроксибензойная кислота) (1). Белые кристаллы, хорошо растворимые в спирте, горячей воде, состава $\mathrm{C}_{7} \mathrm{H}_{6} \mathrm{O}_{5}$, т. пл. $236-238^{\circ} \mathrm{C}$. Выход составил 0,1 г $(0,29 \%$, выход здесь и далее приведен в пересчете на этилацетатное извлечение). УФ-спектр (ЕtOH, $\left.\lambda_{\max } \mathrm{HM}\right): 216,274$. ИК-спектр $\left(\mathrm{KBr}, \mathrm{v}, \mathrm{cm}^{-1}\right)$ : 3490, 3367, 3286 (ОН), 1702 (C=O), 1618, 1542 (Ar). Соединение 1 идентифицировали сопоставлением приведенных выше спектральных характеристик с таковыми в работе [16], а также отсутствием депрессии температуры плавления смешанной пробы вещества 1 с имеющимся образцом галловой кислоты.

Метилгаллат (метиловый эфир 3,4,5-тригидроксибензойной кислоты) (2). Белое порошкобразное вещество, состава $\mathrm{C}_{8} \mathrm{H}_{8} \mathrm{O}_{5}$, т.пл. 200-202 ${ }^{\circ} \mathrm{C}, \mathrm{R}_{f}$ 0,96 (хлороформ - метанол - уксусная кислота - вода, $9: 3: 0,5: 0,5)$. Выход 0,056 г (0,14\%). УФ-спектр (ЕtOH, $\lambda_{\max }$, нм): 221, 276. ИК-спектр (KBr, $\left.v, \mathrm{~cm}^{-1}\right): 3521$,

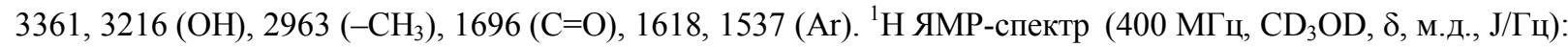
6,99 (1H, с, J=2,0, Н-2, Н-6), 3,75 (3H, с, Н-8). ${ }^{13}$ С ЯМР-спектр (100 МГц, $\mathrm{CD}_{3} \mathrm{OD}, \delta$, м.д.) 121,36 (С-1), 109,98 (С-2, С-6), 146,43 (С-3, С-5), 139,71 (С-4), 169,01 (С-7), 52,29 (С-8). Вещество 2 идентифицировали сопоставлением приведенных выше спектральных характеристик с таковыми метилгаллата, выделенного ранее из Geranium tuberosum L. subsp. tuberosum [17].

Кемпферол (3,5,7,4'-тетрагидроксифлавон) (3). Желтое вещество, состава $\mathrm{C}_{15} \mathrm{H}_{10} \mathrm{O}_{6}$, т.пл. 265 $266{ }^{\circ} \mathrm{C}, \mathrm{R}_{f} 0,75$ (хлороформ - метанол - уксусная кислота - вода, $\left.9: 3: 0,5: 0,5\right)$. Выход 0,08 г (0,23\%). УФспектр (ЕtOH, $\lambda_{\max }$ нм): 257, 358. ИК-спектр $\left(\mathrm{KBr}, v, \mathrm{~cm}^{-1}\right): 3321(\mathrm{OH}), 1662(\mathrm{C}=\mathrm{O}), 1614,1570,1509$ (Ar), 1225, 1195, 1177, 1090 (С-О). Соединение 3 идентифицировали сопоставлением приведенных выше спектральных характеристик с таковыми в работе [18].

Кверцетин (3,5,7,3' $\mathbf{4}^{\prime}$-пентагидроксифлавон) (4). Желтого цвета кристаллы, состава $\mathrm{C}_{15} \mathrm{H}_{10} \mathrm{O}_{7}$, т.пл. 310-312 ${ }^{\circ} \mathrm{C}, \mathrm{R}_{f} 0,63$ (хлороформ - метанол - уксусная кислота - вода, $\left.9: 3: 0,5: 0,5\right)$. Выход составил 0,09 г (0,26\%). УФ-спектр (ЕtOH, $\lambda_{\max }$ нм): 255, 371. ИК-спектр (KBr, v, см $\left.{ }^{-1}\right): 3287(\mathrm{OH}), 1672(\mathrm{C}=\mathrm{O}), 1615,1557$, 1492 (Ar), 1201, 1174, 1166, 1093 (С-О). На основании изучения спектральных данных и сравнения со стандартным образцом соединение 4 идентифицировали с кверцетином [18].

Изорамнетин (3,5,7,4'-тетрагидрокси-3'-метоксифлавон) (5). Желтое вещество, состава $\mathrm{C}_{16} \mathrm{H}_{12} \mathrm{O}_{7}$, т. пл. $306-307^{\circ} \mathrm{C}, \mathrm{R}_{f} 0,53$ (хлороформ - метанол - уксусная кислота - вода, $\left.9: 3: 0,5: 0,5\right)$. Выход составил 0,025 г (0,07\%). УФ-спектр $\left(\mathrm{C}_{2} \mathrm{H}_{5} \mathrm{OH}, \lambda_{\max }\right.$, нм) 371, 265, 254 нм. ИК-спектр $\left(\mathrm{KBr}, v, \mathrm{~cm}^{-1}\right) 3455(\mathrm{OH}), 2895$ $\left(-\mathrm{CH}_{3}\right), 1658(\mathrm{C}=\mathrm{O})$. Соединение 5 идентифицировали на основании сравнения результатов с таковыми имеющегося образца [19].

Изорамнетин-3-O- $\boldsymbol{\beta}$ - $\boldsymbol{D}$-глюкопиранозид (6). Желтое вещество, состава $\mathrm{C}_{22} \mathrm{H}_{22} \mathrm{O}_{12}$, т.пл. $173-175{ }^{\circ} \mathrm{C}$, $\mathrm{R}_{f}$ 0,80 (хлороформ - метанол - уксусная кислота - вода, $\left.9: 3: 0,5: 0,5\right)$. Выход составил 0,095 г $(0,2 \%$, выход здесь и далее приведен в пересчете на $\mu$-бутанольное извлечение). Масс-спектр: $m / z$ 479,1596 $[\mathrm{M}+\mathrm{H}]^{+}$. УФ-спектр $\left(\mathrm{EtOH}, \lambda_{\max } \mathrm{HM}\right): 255,357$. ИК-спектр $\left(\mathrm{KBr}, v, \mathrm{~cm}^{-1}\right): 3479(\mathrm{OH}), 2891\left(-\mathrm{CH}_{3}\right), 1651$ $(\mathrm{C}=\mathrm{O}), 1603,1567,1497$ (Ar), 1092, 1055, 1028, (C-O). ${ }^{1} \mathrm{H}$ ЯМР-спектр (400 МГц, $\mathrm{C}_{5} \mathrm{D}_{5} \mathrm{~N}, \delta$, м.Д., J/Гц): 6,61 $(1 \mathrm{H}$, д, $\mathrm{J}=2,0, \mathrm{H}-6), 6,63$ (1H, д, $\mathrm{J}=2,0, \mathrm{H}-8), 8,40$ (1H, д, J=2.0, H-2'), 7,13 (1H, д, J=8,4, H-5'), 7,66 (1H, дд, $\left.\mathrm{J}=8,4 ; 2,0, \mathrm{H}-6^{\prime}\right), 6,42$ (1Н, д, J=7,6, Н-1"'), 4,16-4,34 (5H, м, Н-2", 3", 4"', 6") , 3,93, (1Н, ддд, J=9,6; 4,7; 2,6, Н$\left.5^{\prime \prime}\right), 3,82\left(3 \mathrm{H}, \mathrm{c}, \mathrm{OCH}_{3}\right), 13,15$ (1H, уш.с, 5-OH). ${ }^{13} \mathrm{C}$ ЯМР-спектр (100 МГц, $\mathrm{C}_{5} \mathrm{D}_{5} \mathrm{~N}, \delta$, м.д.): 157,69 (С-2), 135,15 (C-3), 179,18 (C-4), 163,35 (C-5), 100,51 (C-6), 166,94 (C-7), 95,24 (C-8), 158,13 (C-9), 105,68 (C-10), 122,57 (C-1'), 114,86 (C-2'), 148,51 (C-3'), 151,71 (C-4'), 116,74 (C-5'), 123,58 (C-6'), 103,89 (C-1'), 76,82 $\left(\mathrm{C}-2^{\prime \prime}\right), 79,02\left(\mathrm{C}-3^{\prime \prime}\right), 71,85\left(\mathrm{C}-4^{\prime \prime}\right), 79,62\left(\mathrm{C}-5^{\prime \prime}\right), 62,60\left(\mathrm{C}-6^{\prime \prime}\right)$. Сравнительное изучение спектральных данных с литературными сведениями позволило идентифицировать соединение 6 с изорамнетин-3-O- $\beta-D-$ глюкопиранозидом [20]. 
Изокверцитрин (кверцетин-3-O- $\boldsymbol{\beta}$ - $\boldsymbol{D}$-глюкопиранозид) (7). Желтый порошок, состава $\mathrm{C}_{21} \mathrm{H}_{20} \mathrm{O}_{12}$, т. пл. $236-238{ }^{\circ} \mathrm{C}, \mathrm{R}_{f} 0,71$ (хлороформ - метанол - уксусная кислота - вода, $\left.9: 3: 0,5: 0,5\right)$, хорошо растворимый в метаноле, выход 0,06 г (0,13\%). Масс-спектр: $m / z$ 465,0959 [M+H] $]^{+}$. УФ-спектр $\left(\mathrm{C}_{2} \mathrm{H}_{5} \mathrm{OH}, \lambda_{\max }, \mathrm{HM}\right)$ : 259, 365. ИК-спектр ( $v_{\max }$, см$\left.^{-1}\right): 3183(\mathrm{OH}), 1662(\mathrm{C}=\mathrm{O}), 1608,1566,1507$ (Ar), 1082, 1061, 1012 (C-O), 1273 (C-O-C). ${ }^{1} \mathrm{H}$ ЯМР-спектр (400 МГц, $\mathrm{CD}_{3} \mathrm{OD}, \delta$, м.д., Ј/Гц): 6,29 (1Н, д, J=2,1, Н-6), 6,11 (1H, д, J=2,1, Н-8), 7,65 (1Н, д, J=2,1, Н-2'), 6,80 (1Н, д, J=8,5, Н-5'), 7,51 (1Н, дд, J=8,5; 2,1, Н-6'), 5,19 (1Н, д, J=7,4, Н-1"), 3,44 (1H, м, H-2"), 3,39 (1H, м, H-3"), 3,30 (1H, м, H-4"), 3.18 (1H, ддд, J=7,6; 5,2; 2,3, H-5"), 3,53 (1H, дд, (J=11,9; 5,2, Н-6" $a)$, 3,66 (1Н, дд, J=11,9; 2,3, Н-6"e). ${ }^{13} \mathrm{C}$ ЯМР-спектр (100 МГц, СD $\mathrm{OD}, \delta$, м.д.): 158,49 (С-2), 135,71 (C-3), 179,52 (C-4), 163,05 (C-5), 100,01 (C-6), 166,11 (C-7), 94,86 (C-8), 159,07 (C-9), 105,73 (C-10), 123,13 (C-1'), 116,10 (C-2'), 145,96 (C-3'), 149,93 (C-4'), 117,69 (C-5'), 123,32 (C-6'), 104,45 (C-1'), 75,84 $\left(\mathrm{C}-2^{\prime \prime}\right), 78,19$ (С-3"), 71,27 (C-4"), 78,45 (C-5"), 62,63 (С-6") На основании изучения спектральных данных и сравнения с литературными данными соединение 7 идентифицировали с изокверцитрином [21].

Изорамнетин 3-O-вицианозид (изорамнетин-3-O- $\alpha$-арабинопиранозил-( $\rightarrow$ 6)- $\beta$-глюкопиранозид) (8). Желтый порошок, состава $\mathrm{C}_{27} \mathrm{H}_{30} \mathrm{O}_{16}$, т.пл. $209-210{ }^{\circ} \mathrm{C}, \mathrm{R}_{f}$ 0,34 (хлороформ - метанол - уксусная кислота - вода, $7: 3$ : 0,5 : 0,5). Выход 0,16 г (0,33\%). УФ-спектр (EtOH, $\lambda_{\max }$ нм): 256, 359. ИК-спектр (KBr,

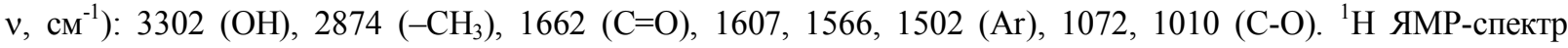
(400 МГц, DMSO-d 6 , $\delta$, м.д., J/Гц): 6,19 (1H, д, J=2,0, Н-6), 6,42 (1H, д, J=2,0, H-8), 7,91 (1Н, д, J=2,1, Н-2'), $6,92(1 \mathrm{H}$, д, J=8,5, Н-5'), 7,52 (1H, дд, J=8,5; 2,1, Н-6'), 12,56 (уш.с, 5-ОН), 5,46 (1H, д, J=7,3, Н-1"'), 3,25 (2H,

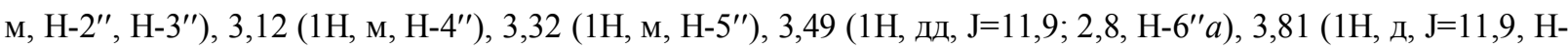

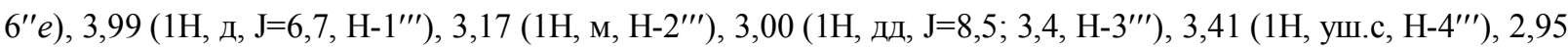
$\left(1 \mathrm{H}\right.$, д, $\left.\mathrm{J}=11,6, \mathrm{H}-5^{\prime \prime \prime} a\right), 3,48\left(1 \mathrm{H}\right.$, д, $\left.\mathrm{J}=11,6, \mathrm{H}-5^{\prime \prime \prime} e\right), 3,84\left(3 \mathrm{H}, \mathrm{c}, \mathrm{OCH}_{3}\right) .{ }^{13} \mathrm{C}$ ЯМР-спектр (100 MГц, DMSO-d 6 , $\delta$, м.д.): 156,14 (C-2), 133,00 (C-3), 177,26 (C-4), 161,16 (C-5), 98,83 (C-6), 164,59 (C-7), 93,76 (C-8), 156,43 (C-9), 103,89 (C-10), 120,97 (C-1'), 113,24 (C-2'), 146,93 (C-3'), 149,47 (C-4'), 115,27 (C-5'), 122,09 (C-6'),

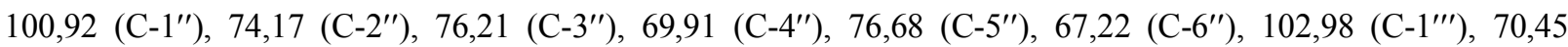

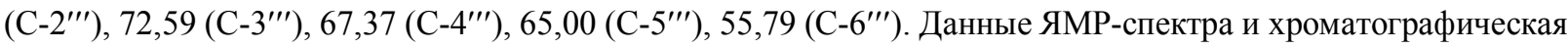
подвижность свидетельствуют о том, что выделенное соединение является гликозидом. При кислотном гидролизе этого соединения были получены агликон состава $\mathrm{C}_{16} \mathrm{H}_{12} \mathrm{O}_{7}$, т. пл. 306-307 ${ }^{\circ} \mathrm{C}$, УФ-спектр $\left(\mathrm{C}_{2} \mathrm{H}_{5} \mathrm{OH}, \lambda_{\max }, \mathrm{Hм}\right) 371,265,254$ нм, и $D$-глюкоза и $L$-арабиноза. При этом выявили наличие $D$-глюкозы и $L$-арабинозы со значением $\mathrm{R}_{f}-0,31 ; 0,39$ (н-бутанол - пиридин - вода, $6: 4: 3$ ) соответственно. Сравнением физико-химических свойств и изучением спектральных данных агликон идентифицировали с изорамнетином [19]. Обобщая полученные данные, а также сравнивая с литературными данными, соединение 8 идентифицировали с изорамнетин 3-О-вицианозидом [22].<smiles>[R]OC(=O)c1cc(O)c(O)c(O)c1</smiles><smiles>[R2]Oc1c(-c2ccc(O)c([R2])c2)oc2cc(O)cc(O)c2c1=O</smiles>
1. $\mathrm{R}=\mathrm{H}$
3. $\mathrm{R}_{1}=\mathrm{H} ; \mathrm{R}_{2}=\mathrm{H}$
6. $\mathrm{R}_{1}=-\beta-\mathrm{D}-\mathrm{Glc} p ; \mathrm{R}_{2}=\mathrm{OCH}_{3}$
2. $\mathrm{R}=\mathrm{CH}_{3}$
4. $\mathrm{R}_{1}=\mathrm{H} ; \mathrm{R}_{2}=\mathrm{OH}$
7. $\mathrm{R}_{1}=-\beta-\mathrm{D}-\mathrm{Glc} p ; \mathrm{R}_{2}=\mathrm{OH}$
5. $\mathrm{R}_{1}=\mathrm{H} ; \mathrm{R}_{2}=\mathrm{OCH}_{3}$
8. $\mathrm{R}_{1}=-\alpha-\operatorname{Ara} p(1-6)-\beta-\mathrm{D}-\mathrm{Glc} p ; \mathrm{R}_{2}=\mathrm{OCH}_{3}$

\section{Bblводы}

Таким образом, согласно проведенным фитохимическим исследованиям, впервые показано, что надземная часть растения G. charlesii является источником биологически активных фенольных соединений - галловой кислоты (1), метилгаллата (2), кемпферола (3), кверцетина (4), изорамнетина (5), изорамнетин 3-O- $\beta$-Dглюкопиранозида (6), изокверцитрина (7), изорамнетин 3-O-вицианозида (8). Следует отметить, что соединения 1-4 и 7 ранее были выделены из Geranium saxatile и Geranium tuberosum L. subsp. tuberosum [16-18], a 5, 6, 8 впервые были выделены из Geranium charlesii и в целом из растения рода Geranium. 
Преобладающими по содержанию этого виды Geranium являются галловая кислота (1) и изорамнетин 3-O-вицианозид (8).

\section{Список литературы}

1. Mabberley D.J. The Plant Book. United Kingdom; London, 1997. 858 p.

2. Комарова В.Л. Герань - Geranium L. // Флора СССР. М.; Л., 1949. Т. ХІ. С. 2-62.

3. Определитель растений Средней Азии. Критерический конспект флоры. Ташкент, 1983. Т. VII. С. 6-14.

4. лора Узбекистана. Ташкент, 1959. T. IV. С. 23-33.

5. Тожибаев К.Ш. Флора Юго-Западного Тянь-Шаня (в пределах Республики Узбекистан). Ташкент, 2010. 100 с.

6. Растительные ресурсы СССР. Цветковые растения, их химический состав, использование. Семейства Rutaceae-Elaeagnaceae. Л., 1988. Т. IV. С. 37-47.

7. Li J., Huang H., Feng M., Zhou W., Shi X., Zhou P. In vitro and in vivo anti hepatitis B virus activities of a plant extract from Geranium carolinianum L. // Antiviral Research. 2008. Vol. 79. Pp. 114-120.

8. Zhang X.Q., Gu. H.M., Li X.Z., Xu Z.N., Cheng Y.S., Li.Y. Anti-Helicobacter pylori compounds from the ethanol extracts of Geranium wilfordii // Journal of Ethnopharmacology. 2013. Vol. 147. Pp. 204-207.

9. Rodriguez J., Loyola J.I., Maulen G., Hirschmann G.S. Hypoglycaemic activity of Geranium core-core, Oxalis rosea and Planto major extract in rats // Phytotherapy Research. 1994. Vol. 8. Pp. 372-374.

10. Amabeoku G.J. Antidarrhoeal activity of Geranium incanum Burm. f. (Geraniaceae) leaf aqueous extract in mice // Journal of Ethnopharmacology. 2009. Vol. 123. Pp. 190-193.

11. Murzakhmetova M., Moldakarimov S., Tancheva L., Abarova S., Serkedjieva J. Antioxidant and prooxidant properties of a polyphenol-rich extract from Geranium sanguineum L. In vitro and in vivo // Phytotherapy Research. 2008. Vol. 22. Pp. 746-751.

12. Montejano-Rodrigues J.R., Almaguer-Vargas G., Gayosso-De-Lucio J.A., Ocharan Hernandes M.E., Moreno Martinez R.E., Hernandes Caballero M.E., Torres-Valencia J.M., Sierra Rameres J.A. Evaluation of the diuretic activity of the ethanolic extract of Geranium seemannii Peyr. In Wistar rats // Journal of Pharmacy Research. 2013. Vol. 6. Pp. 709-713.

13. Calzada F., Cervantes-Martinez G.A., Yepez-Mulia L. In vitro antiprotozoal activity from the roots of Geranium mexicanum and its constituents on Entamoeba histolytica and Gardia lamblia // Journal of Ethnopharmacology. 2005. Vol. 98. Pp. 191-193.

14. Shim J.U., Oh P.S., Lim K.T. Anti-inflammatory activity of ethanol extract from Geranium sibiricum Linne. // Journal of Ethnopharmacology. 2009. Vol. 126. Pp. 90-95.

15. Чеврениди С.Х. Дубильные растения Средней Азии. Ташкент, 1965. 330 с.

16. Siddikov D.R., Nishanbaev S.Z., Narbutaeva D.A., Vdovin A.D., Abdullaev N.D. Polyphenols from Geranium saxatile // Chemistry of Natural Compounds. 2011. Vol. 47. Pp. 630-631.

17. Sohretoglu D., Sakar M.K., Sabuncuoglu S.A., Ozgunes H., Sterner O. Antioxidant galloylated flavonoids from Geranium tuberosum L. subsp.tuberosum. // Turkish journal of chemistry. 2009. Vol. 33. Pp. 685-692.

18. Siddikov D.R., Nishanbaev S.Z., Narbutaeva D.A., Bobakulov Kh.M. Secondary metabolites from the aerial part of Geranium saxatile // Chemistry of Natural Compounds. 2013. Vol. 49. Pp. 343-344.

19. Sikorska M., Matlawska I. Kaempferol, isorhamnetin and their glucosides in the flowers in the Asclepias syriaca L.// Acta Poloniae Pharmaceutica-Drug Research. 2001. Vol. 58. Pp. 269-272.

20. Гужва Н.Н. Биологически активные вещества астрагала эспарцетного, произрастающего в Предкавказье // Химия растительного сырья. 2009. № 3. С. 123-132.

21. Zhang G., Guo M.L., Li R.P., Li Y., Zhang H.M., Su Z.W. A novel compound from Flos carthami and its bioactivity // Chemistry of Natural Compounds. 2009. Vol. 45. Pp. 398-401.

22. Sakar M.K., Engelshowe R., Friedrich H. Ein neues Flavonglukosid aus den Blattern von Papaver orientale // Planta Medica. 1980. Vol. 40. Pp. 193-196. 
Siddikov D.R.*, Bobakulov Kh.M., Nishanbayev S.Z., Abdullaev N.D. PHENOLIC COMPOUNDS FROM AERIAL PARTS OF GERANIUM CHARLESII (AITCH. \& HEMSL.) VVED.

Acad. S. Yu.Yunusov Institute of the Chemistry of Plant Substances Uzbek Academy of Sciences, ul. Mirzo Ulugbeka,

77, Tashkent,100170(Uzbekistan),e-mail:drsiddiqov@mail.ru

The phenolic compounds from the aerial part (stems, leaves and flowers) of Geranium charlesii (Aitch. \& Hemsl.) Vved. (Geranium of Charles from family Geraniaceae) growing in Uzbekistan were studied. For the first time from this type of geranium by column chromatography from ethyl acetate and n-butanol fraction of $70 \%$ ethanol extract sequentially isolated phenolic compounds. At the separation of the ethylacetate fraction by column chromatography identified five individual compounds, including gallic acid (1) methyl gallate (2), kaempferol (3), quercetin (4) and isorhamnetin (5) and from n-butanol fractions - isorhamnetin 3-O- $\beta$-D-glucopyranoside (6) isoquercitrin (7), isorhamnetin-3-O-vicianoside (8).

According to our phytochemical studies first time showed that aerial part of the plant G. charlesii is a source of biologically active phenolic compounds $1-8$. It should be noted that compounds $1-4$ and 7 have been previously isolated from Geranium saxatile and Geranium tuberosum L. subsp. tuberosum, and 5, 6, 8, were first time isolated from Geranium charlesii in whole plants from the genus Geranium. The predominant by content of this species Geranium are gallic acid (1) and isorhamnetin-3-O-vicianoside (8). The compounds were identified on the basis of the physical and chemical methods, IR, UV, NMR spectroscopy and mass-spectrometry.

Keywords: Geranium charlesii (Aitch. \& Hemsl.) Vved. Geraniaceae, phenolcarboxylic acid, flavonols and flavonolglucosides.

\section{References}

1. Mabberley D.J. The Plant Book. United Kingdom; London, 1997, 858 p.

2. Komarova V.L. Flora SSSR. [Flora of the USSR]. Moscow; Leningrad, 1949, vol. XI, pp. 2-62. (in Russ.).

3. Opredelitel' rastenii Srednei Azii. Kritericheskii konspekt flory. [The determinant of plants of Central Asia. Critical summary of flora]. Tashkent, 1983, vol. VII, pp. 6-14. (in Russ.).

4. Flora Uzbekistana. [Flora of Uzbekistan]. Tashkent, 1959, vol. IV, pp. 23-33. (in Russ.).

5. Tozhibaev K.Sh. Flora Iugo-Zapadnogo Tian'-Shania (v predelakh Respubliki Uzbekistan). [Flora of the SouthWestern Tien-Shan (within the Republic of Uzbekistan)]. Tashkent, Fan, 2010, 100 p. (in Russ.).

6. Rastitel'nye resursy SSSR. Tsvetkovye rasteniia, ikh khimicheskii sostav, ispol'zovanie. Semeistva RutaceaeElaeagnaceae. [Plant resources of the USSR. Flowering plants, their chemical composition, use. Families of Rutaceae-Elaeagnaceae]. Leningrad, 1988, vol. IV, pp. 37-47. (in Russ.).

7. Li J., Huang H., Feng M., Zhou W., Shi X., Zhou P. Antiviral Research, 2008, vol. 79, pp. 114-120.

8. Zhang X.Q., Gu. H.M., Li X.Z., Xu Z.N., Cheng Y.S., Li.Y. Journal of Ethnopharmacology, 2013, vol. 147, pp. $204-207$.

9. Rodriguez J., Loyola J.I., Maulen G., Hirschmann G.S. Phytotherapy Research, 1994, vol. 8, pp. 372-374.

10. Amabeoku G.J. Journal of Ethnopharmacology, 2009, vol. 123, pp. 190-193.

11. Murzakhmetova M., Moldakarimov S., Tancheva L., Abarova S., Serkedjieva J. Phytotherapy Research, 2008, vol. 22, pp. 746-751.

12. Montejano-Rodrigues J.R., Almaguer-Vargas G., Gayosso-De-Lucio J.A., Ocharan Hernandes M.E., Moreno Martinez R.E., Hernandes Caballero M.E., Torres-Valencia J.M., Sierra Rameres J.A. Journal of Pharmacy Research, 2013, vol. 6, pp. 709-713.

13. Calzada F., Cervantes-Martinez G.A., Yepez-Mulia L. Journal of Ethnopharmacology, 2005, vol. 98, pp. $191-193$.

14. Shim J.U., Oh P.S., Lim K.T. Journal of Ethnopharmacology, 2009, vol. 126, pp. 90-95.

15. Chevrenidi S.Kh. Dubil'nye rasteniia Srednei Azii. [Tanning plants of Central Asia]. Tashkent, 1965,330 p. (in Russ.).

16. Siddikov D.R., Nishanbaev S.Z., Narbutaeva D.A., Vdovin A.D., Abdullaev N.D. Chemistry of Natural Compounds, 2011, vol. 47, pp. 630-631.

17. Sohretoglu D., Sakar M.K., Sabuncuoglu S.A., Ozgunes H., Sterner O. Turkish journal of chemistry, 2009, vol. 33, pp. 685-692.

18. Siddikov D.R., Nishanbaev S.Z., Narbutaeva D.A., Bobakulov Kh.M. Chemistry of Natural Compounds, 2013, vol. 49, pp. 343-344.

19. Sikorska M., Matlawska I. Acta Poloniae Pharmaceutica-Drug Research, 2001, vol. 58, pp. 269-272.

20. Guzhva N.N. Khimiia rastitel'nogo syr'ia, 2009, no. 3, pp. 123-132. (in Russ.).

21. Zhang G., Guo M.L., Li R.P., Li Y., Zhang H.M., Su Z.W. Chemistry of Natural Compounds, 2009, vol. 45, pp. $398-401$.

22. Sakar M.K., Engelshowe R., Friedrich H. Planta Medica, 1980, vol. 40, pp. 193-196. 